\title{
Forensic evidence - a rape and murder case
}

\begin{abstract}
Sexual crime is very alarming in most of the countries and India is not exception to it. As per National Crime Records Bureau (NCRB), MHA, Govt. of India data, every day ninety three women are being raped in the country. There is also gradual increase in the number of rapes reported in India. But incident of rape-sexual homicide cases are very less, as such the data on commission of two different unrelated crimes together are not available in literature. In one case, a girl age about 20-year was found lying dead in half naked condition being strangulated with a full pant tied around her neck in an abandoned place. The incident was reported to the police and investigating officer along with forensic team visited the undisturbed violent crime scene to study the crime scene behavior and collect different forensic evidence. Further, autopsy report and analysis of the forensic evidence could help to establish the crime and apprehend the rapist. The details have been discussed in this paper.
\end{abstract}

Keywords: rape, sexual homicide, crime scene, criminal profile, forensic evidence
Volume 7 Issue 2 - 2019

\section{Sabyasachi Nath, HK Pratihari}

State Forensic Science Laboratory, Tripura, India

Correspondence: Sabyasachi Nath, State Forensic Science Laboratory, Tripura-7990 I5, India, Tel +9I-943645465I, Fax +91-038I2341266, Email drsabyasachinath@gmail.com

Received: March 12,2019 | Published: April 18, 2019
Abbreviations: NCRB, national crime records bureau; IPC, Indian penal code; POCSO Act, protection of children from sexual offence act

\section{Introduction}

Various nature of crimes like murder, rape, assault, suicide, disputed paternity, fraud, accident, acid burning, hacking, poisoning etc. are reported and punishable under different sections of the Indian Penal Code, POCSO/Anti-Dowry Act and other Laws. Among different crimes, the rape and murder are very heinous. Both are unrelated crimes coming under different major heads prescribing stringent punishment under different sections of IPC. As per National Crime Records Bureau (NCRB) report, 30,450murder cases and 38,947rape cases were registered in the year 2016. ${ }^{1}$ Both the crimes were committed by different psychological mechanism and behavioral activities. The study reveals that rape cases are reported due to sexual intimacy and in more than $90 \%$ cases victims are known to their assailants either friend, relative or neighbor and the rest $10 \%$ are stranger. ${ }^{2}$ But sexual homicide (rape-murder) is comparatively less and statistical data is also not available in literature. ${ }^{3}$ In sexual-homicide cases, the behavior of the accused is observed to be different than normal sexual offenders. ${ }^{4}$ The rape followed with murder is heinous and committed with aggressive behavior under different situations of the offender resulting death of victim. In such case, physical examination of the victim should be done from head-to-toe conducting with genitoranal area to establish the profile of the criminal. The different factors reported to kill the victim in sexual homicide cases are capsulized in Figure $1 .^{3-7}$

\section{Case report}

In this case, a girl age about 20-year was living alone in a rented house in the outskirt of a city. She was not well known to the locals but suspected having loose character. One day, the girl was found lying dead in half-naked condition in an abandoned place with a long pant (wearing apparel of the deceased girl) being tied around her neck with bleeding signs from nostrils/mouth. Further, the crime scene behavior was violent in nature and investigation was made to establish the physical evidence and psychology of the criminal.

\section{Observation}

The position of the deceased at scene of crime and other injuries on the dead body, are shown in Figures 2-5.

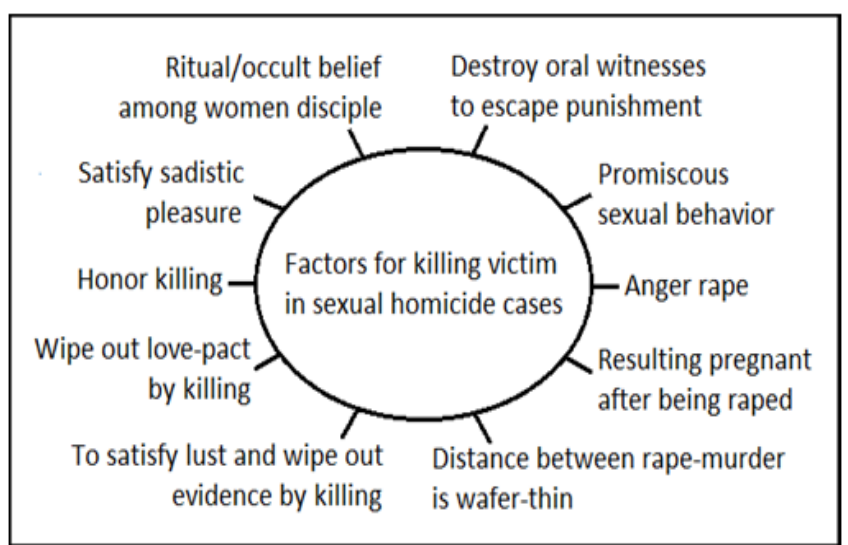

Figure I Factors for killing victim in sexual homicide cases.

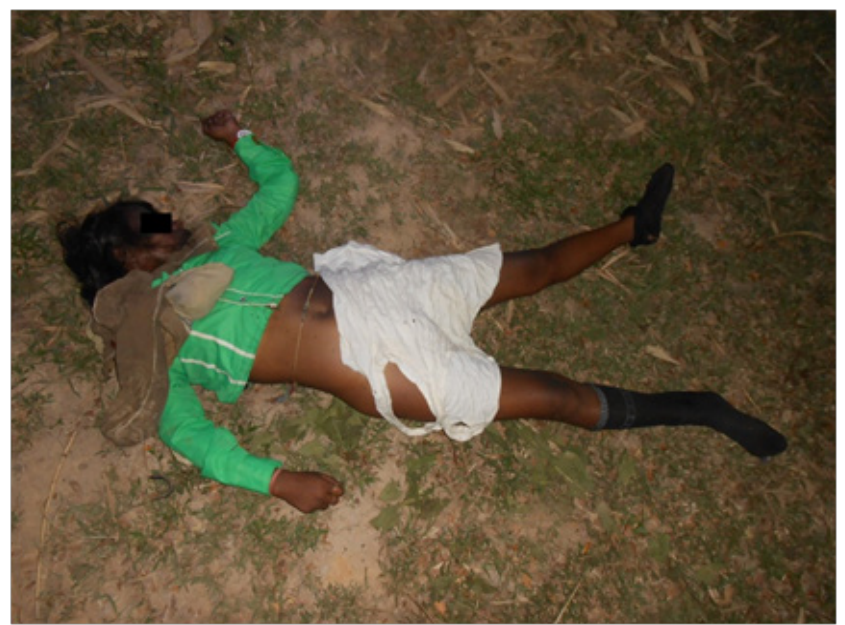

Figure 2 Victim lying dead in half naked condition. 


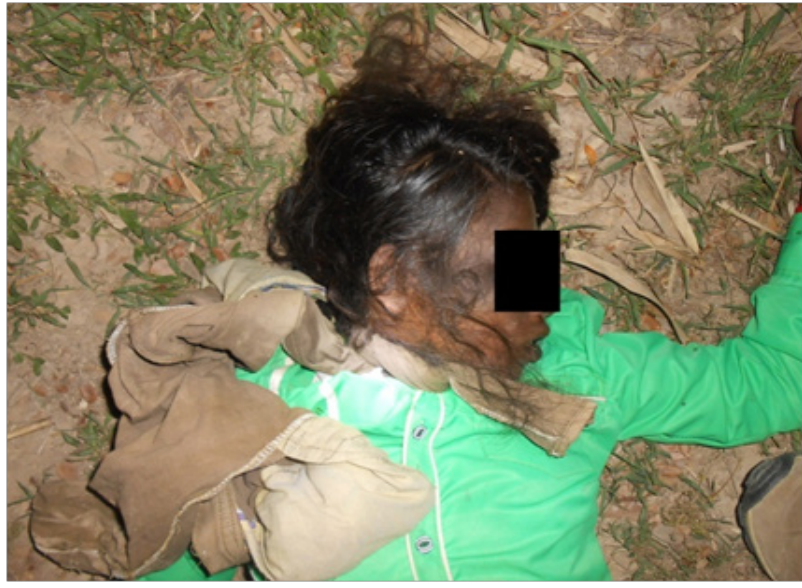

Figure 3 Victim was strangulated with a long pant tied around her neck.

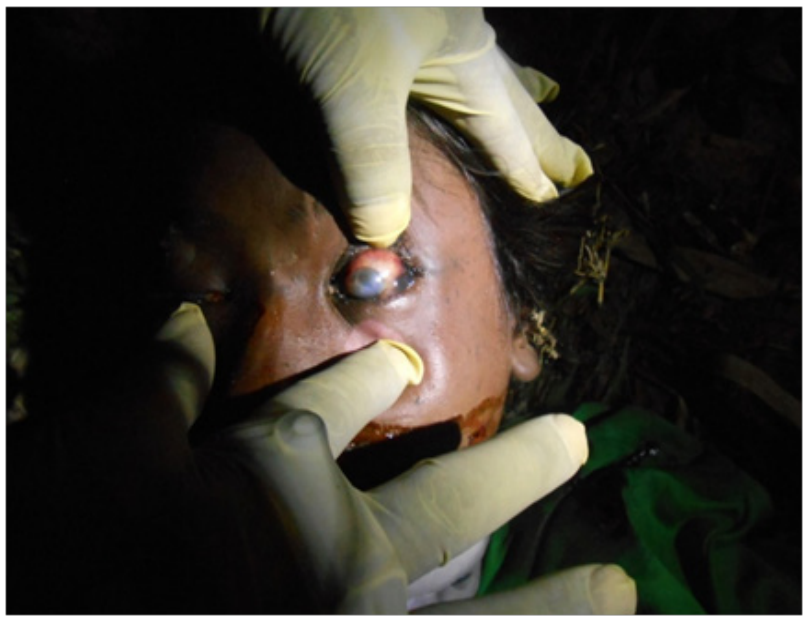

Figure 4 Victim with sub-conjunctival haemorrhage.

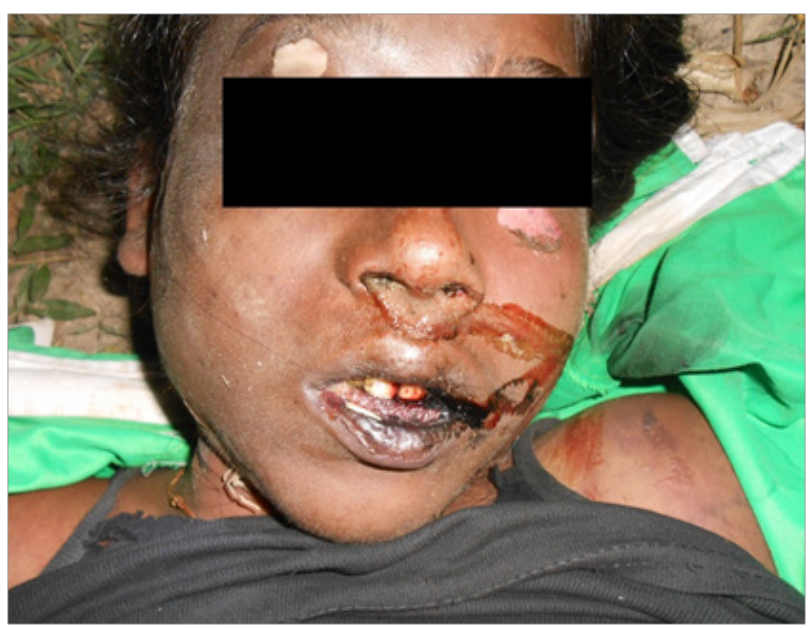

Figure 5 Bleeding from nostrils and mouth of the victim.

\section{Physical evidence detected at undisturbed crime scene for forensic analysis}

I. Violent sexual behavior showing the victim lying half naked with a pant tied around her neck,
II. Blood stained soil was present on the spot,

III. Disturbed shoe prints were available, but not useful for examination/comparison,

IV. Victim was found on the spot with socks but without shoes indicating the body was dragged from a distance,

V. Dragging mark was present on the spot,

VI. Mud stain collected from the wearing apparel of the victim,

VII. Control soil sample collected from nearby the area for comparison,

VIII. Vaginal swab, oral swab, anal swab, pubic hair, fingernail scraping were collected during post mortem for examination/ comparison,

IX. Hair collected from wearing apparel of the victim,

$\mathrm{X}$. Use of force on the neck of the victim showing some nail marks,

XI. Tongue was caught between the teeth of upper and lower jaws,

XII. Bleeding from nostrils and mouth indicates the sign of strangulation,

XIII. Inquest was made properly followed with post mortem examination.

\section{Autopsy findings}

\section{External}

Eyes are partially open; cornea of both the eyes is opaque and the eye balls are depressed due to decomposition. Blood tinged discharge is coming out of the nose and mouth. Mouth is partially open; tip of the tongue is caught in between the teeth of upper and lower jaw. Anal opening is dilated with whitish color discharge coming out of it. No tears or skin tags are seen in the anal orifice. Frenulum in the oral cavity is intact. No injuries are present on the lip. Dark brown color abraded, dry, hard, parchment like ligature mark is present incompletely and almost horizontally around the neck. The neck circumference is $30 \mathrm{~cm}$. On the front of neck, the mark is $3 \mathrm{~cm}$ below the chin and $7 \mathrm{~cm}$ above the suprasternal notch in the midline. On the right side of neck, the mark is $2 \mathrm{~cm}$ below the tip of right mastoid process. Thereafter the mark goes backwards and downwards and ends on the upper part of shoulder on right side and ends $5 \mathrm{~cm}$ from midline. On left side of neck, the mark is $1.5 \mathrm{~cm}$ below the tip of left mastoid process. Thereafter, the mark is absent on the back of neck for a distance of $11 \mathrm{~cm}$. Maximum width of ligature make is $5 \mathrm{~cm}$ just below the left angle of mandible. Multiple old healed tears are present in 3, 5, 7 and 9 o'clock position on the hyman and the vaginal rugosities can be seen through the orifice.

\section{Internal}

On dissection, bruising is present in the soft tissue and muscles of the neck on right side on the lateral aspect. Epiglottis is congested; hyoid bone and thyroid cartilage are intact. Ante mortem injuries:

I. Bruising is present in the layers of the muscles and soft tissue around the hyoid bone and thyroid cartilage on right side;

II. Contusion measuring $3 \times 2.5 \mathrm{~cm}$ is present on the right side of face, $6.5 \mathrm{~cm}$ from midline and just below the outer angle of right eye; 
III. Reddish color abrasion measuring $7 \times 2 \mathrm{~cm}$ is present obliquely on the back of right leg, $6 \mathrm{~cm}$ below the popliteal fossa.

Ages of injuries are fresh at the time of death. The toxicological analysis of viscera and body fluid ruled out the presence of poison and drug in this case.

\section{Discussion}

This is an unusual rape-sexual homicide case and trail of events suggest the accused after sex had hot arguments and in a fit of anger lost mental balance. Being aggrieved strangulated the victim showing injury mark around the neck. In order to further satisfy anger, even the full pant of the girl was used to tie around the neck for further confirmation of death resulting found naked. The immediate identification of the accused was difficult; however, during interrogation to the locals, one of the persons admitted to have seen the victim (girl) with a local boy before the incident. The police made intensive search and accused was apprehended. During rigorous interrogation, the accused admitted to have killed the victim for getting threat on various issues. The result of forensic examination of vaginal/anal swab collected from victim matched with that of the accused person. This further confirmed the charge of rape and murder in this case.

\section{Acknowledgments}

The authors are thankful to the autopsy surgeons for providing necessary documents in this case.

\section{Conflicts of interest}

The author declares that there are no conflicts of interest.

\section{References}

1. National Crime Records Bureau. Ministry of Home Affairs, Government of India. 2016.

2. Whealin J. Child Sexual Abuse, National Center for Post Traumatic Stress Disorder. US Department of Veterans Affairs. 2007.

3. Nath S, Pratihari HK. Gang Rape and Murder - A Case Report. J Forensic Sci \& Criminal Inves. 2018;10(1):1-4.

4. Salfati CG, Taylor P. Differentiating sexual violence: A comparison of sexual homicide and rape. Psychology, Crime \& Law, Taylor \& Francis Group. 2006;12(2):107-125.

5. Fisher Barry AJ. Techniques of crime scene investigation. Seventh Edition. CRC Press LLC. 2004.

6. Becker Ronald F. Criminal Investigation. Third Edition. Jones and Bartlett Publishers. 2009.

7. Nath S, Pratihari HK. Why Murder After Rape? J Forensic Sci \& Criminal Inves. 2018;11(1):1-3. 